\title{
Geological and Geomorphological Characteristics of High-Priority Landing Sites for the Luna-Glob Mission
}

\author{
S. S. Krasilnikov ${ }^{a}, *$, A. T. Basilevsky ${ }^{a}$, M. A. Ivanov ${ }^{a}$, and A. S. Krasilnikov ${ }^{a}$ \\ ${ }^{a}$ Vernadsky Institute of Geochemistry and Analytical Chemistry, Russian Academy of Sciences, Moscow, Russia \\ *e-mail: krasilnikovruss@gmail.com \\ Received July 17, 2020; revised September 11, 2020; accepted September 16, 2020
}

\begin{abstract}
The geomorphological and geological analysis of the surface of three primary and ten secondary landing ellipses $(15 \times 30 \mathrm{~km})$ for the Russian Luna-Glob automated scientific station (Luna-25) is presented. The earlier selected landing ellipses are found in the sector of $65^{\circ}-85^{\circ} \mathrm{S}$ and $0^{\circ}-60^{\circ} \mathrm{E}$ of the lunar southern hemisphere. The geological characteristics of the ellipse include the analysis of the surface age and the identification of the material sources. The analyses of water equivalent hydrogen concentration in the sector of landing and rock content on the surface are also carried out. The constraints, such as the surface inclination and the characteristic of the spacecraft's flight path are used for prioritization of the ellipses from an engineering-technical perspective. According to the results of the study, landing ellipses 1, 3, 4, 6 and 8 are determined as high-priority, while ellipses 5, 7, 9, 10, 11, as well as B1 and B2 are found the least favorable.
\end{abstract}

Keywords: Moon, Luna-Glob, Luna-25, landing site

DOI: $10.1134 / \mathrm{S} 0038094621010056$

\section{INTRODUCTION}

A sector in the lunar southern hemisphere with the coordinates $65^{\circ}-85^{\circ} \mathrm{S}$ and $0^{\circ}-60^{\circ} \mathrm{E}$ was selected for landing the Luna-Glob spacecraft (Luna-25) from an engineering perspective; it satisfies best the ballistic constraints of the expedition and the condition of ground communication (Djachkova et al., 2017). In selecting the landing ellipses in this sector, it is necessary to take into account two required components, technical and scientific, of the expedition to be worked out. The technical component includes the adjustment of the technology for soft landing and the longterm operation under conditions of the lunar pole. The scientific component depends on the major scientific goal of the expedition and, consequently, on the devices mounted onboard the spacecraft.

At present, we can identify a few of the most important areas in studying the Solar System bodies using a lander module and an orbiter: (1) the soil analysis to determine the composition and a possible origin of source rocks; (2) searching for water in the nearsurface layer of soil and on the surface; (3) searching for complex organic compounds and methane that suggest the potential presence of life on this body in the past or in the present.

A high-priority research area for the Luna-Glob expedition is the regolith analysis by the lander module in the lunar south pole area, where according to the neutron spectroscopy results, areas of increased content of hydrogen in regolith have been detected; this is considered a sign of the existence of ice (Feldman et al., 2001; Sanin et al., 2017; Ivanov et al., 2017; Li et al., 2018).

A geological and geomorphological structure of the surface is also extremely important from the scientific perspective, which will make it possible to relate the results of soil analysis to a local or even regional geological context. The topographic diversity will provide a much more complete result for the geological analysis and will make it possible to better study impact and slope processes in the lunar south pole area. The presence of the material thrown out of the SPA cover will allow us to analyze the most ancient lunar rocks.

However, for safe landing and successful operation of the lander module in the southern circumpolar region, which has strongly dissected relief, it is necessary to fulfill four main engineering-technical requirements (Djachkova et al., 2017).

(1) The selection of a flight orbit: the topography at an approach to the landing site should not create a hazard of impacting the surface.

(2) The surface inclination at the landing site should not exceed $7^{\circ}-10^{\circ}$ at the base comparable to the diameter of the lander module (the first few meters). This requirement will allow avoiding a spacecraft roll-over.

(3) Duration and stability of radio communication sessions. Due to a large volume of transmitted information, it is of utmost importance that the spacecraft 


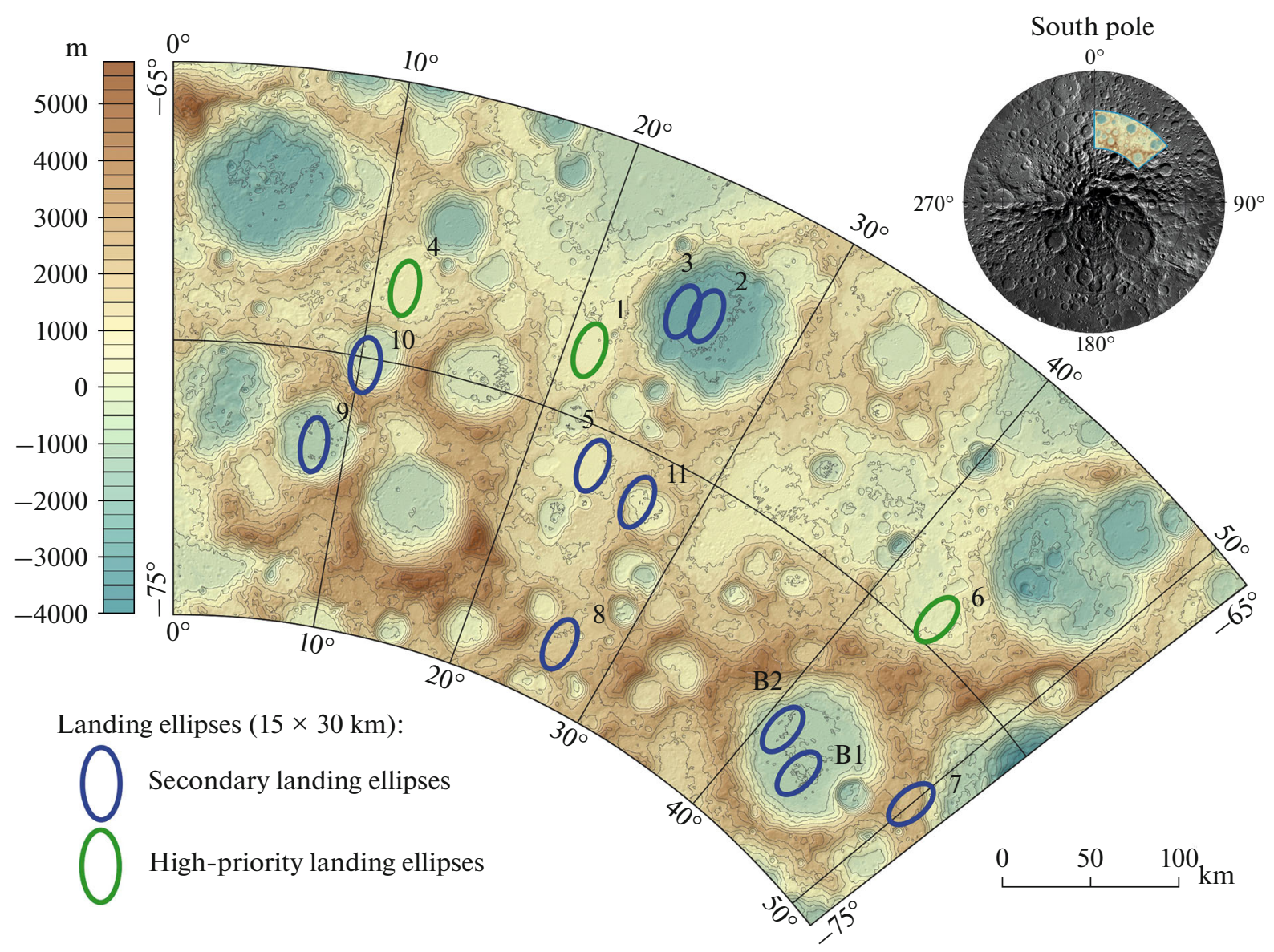

Fig. 1. Suggested landing ellipses for Luna-Glob (Luna-25). Primary ellipses are 1, 4, 6 and secondary ellipses are 2, 3, 5, 7, 8, 9, 10,11 and B1, B2.

has the greatest period of radiovisibility from the Earth.

(4) The angle of solar rays incidence on the upper radiator panel should not exceed $20^{\circ}$, which will not allow the module to overheat. The duration of module lighting should be at least $40 \%$ of the lunar day. The lighting conditions depend strongly on local inclinations and exposure at a landing site, as well as impose a restriction on the geographical latitude of landing, $>65^{\circ} \mathrm{S}$.

Eleven landing ellipses were proposed and preliminarily analyzed for conformity to engineering constraints in (Djachkova et al., 2017). The ellipses were ranged from the most favorable to the least favorable landing sites in (Djachkova et al., 2017; Krasilnikov et al., 2018). On the totality of technical parameters, ellipse 1 was selected as the primary landing ellipse and ellipses 4 and 6 were secondary ones (Djachkova et al., 2017). Two ellipses in Boguslawsky crater, which were previously considered as primary, Boguslawsky-1 $\left(73.9^{\circ} \mathrm{S} ; 43.9^{\circ} \mathrm{E}\right.$, hereinafter B1) and Boguslawsky-2 $\left(72.9^{\circ} \mathrm{S} ; 41.3^{\circ} \mathrm{E}, \mathrm{B} 2\right)$ (Fig. 1), were analyzed in (Ivanov et al., 2015; Krasilnikov et al., 2018). The geology of three primary landing ellipses $(1,4$, and 6$)$ was described in (Ivanov et al., 2018). The geology of eight secondary landing ellipses $(2,3,5,7,8,9,10$, and 11 , Fig. 1) remained unstudied. Nevertheless, when the plans of the Luna-Glob expedition are adjusted, some of these ellipses can be assigned the highest priority. Consequently, the substantiated selection of a landing site from the scientific and engineering perspectives also requires a geological-morphological analysis of the ellipses that are used to be considered secondary.

The analysis of the secondary landing sites of the spacecraft is based on the data obtained using the following instruments mounted on the Lunar Reconnaissance Orbiter spacecraft: (1) optical cameras WAC (Wide Angle Camera) with a resolution of $100 \mathrm{~m} / \mathrm{px}$ and NAC (Narrow Angle Camera) with a resolution of $0.5-1.0 \mathrm{~m} / \mathrm{px}$ (Robinson et al., 2010). These data formed the basis for the photogeological analysis of the study region; (2) a LOLA (Lunar Orbiter Laser Altimeter), the measurements of which were used for topographic mapping with a spatial resolution of $60 \mathrm{~m} / \mathrm{px}$ in our study region (Smith et al., 2010); (3) a neutron detector LEND (Lunar Exploration Neutron Detector) with a nominal spatial resolution of $10 \mathrm{~km}$ (Mitrofanov et al., 2010). These data make it possible 
to estimate a hydrogen content in $\sim 1$-m thick upper layer of regolith; (4) and the Diviner infrared radiometer, whose data enable estimating a model degree of rock content on the surface, which is important for assessment of risk associated with landing at a certain site (Paige et al., 2010).

Using these data in our study, we analyzed the topography of the flight paths, performed geological mapping of all ellipses, identified the potential sources of material, which was accumulated and displaced within the ellipses, determined the frequency distribution of the inclinations and analyzed the frequencysize distribution of the rocks and the craters within the secondary landing ellipses.

\section{ANALYSIS OF TOPOGRAPHY OF FLIGHT PATHS TO THE LANDING ELLIPSES}

To analyze the topography, digital terrain models (DTMs) were used in the flight path of the lander according to the LOLA data. The width of the study sector is equal to the maximum width of the landing ellipse $(15 \mathrm{~km})$, and its length is $200 \mathrm{~km}$. For the landing sector, the averaged surface profile was calculated.

The flight paths of the lander can be divided into two classes with significant and insignificant differences in elevation relative to the average elevation of a landing ellipse. The first class includes ellipses 5, 7, 8, and 11. The second class-ellipses 2, 3, 9, 10, B1, and B2. The first-class ellipses are located on a comparatively plain surface of the ejecta from the impact craters $(5,7,8)$, or a crater rim is expressed insignificantly (ellipse 11). All second-class ellipses are found on the floor of the impact craters, in which the rim is located in the immediate vicinity of the landing site, may cause a threat during a spacecraft descent. The information obtained should be taken into consideration during landing, since the spacecraft may be stuck on high protrusions during a very shallow descent; however, it should not be a limiting factor in selecting a site, as the final landing path will be calculated before launching the spacecraft.

\section{ESTIMATES OF ICE DISTRIBUTION IN THE SECTOR OF LUNA-GLOB EXPEDITION}

The analysis of the LEND data (Sanin et al., 2017) within all selected landing ellipses allowed us to determine the character of variations in the water equivalent hydrogen $(\mathrm{WEH})$ in the near-surface $(\sim 1 \mathrm{~m})$ regolith layer (Fig. 2). The highest concentration of WEH is recorded in ellipses 7 and 10, where the average values of WEH are $0.19 \pm 0.02$ (hereinafter $1 \sigma$ ) and $0.14 \pm$ $0.01 \mathrm{wt} \%$, respectively. The smallest values of WEH characterize ellipses $5(0.07 \pm 0.02 \mathrm{wt} \%), 9(0.06 \pm$ $0.02 \mathrm{wt} \%)$ and B-1 $(0.01 \pm 0.01 \mathrm{wt} \%)$; in landing ellipse B-2, the values of WEH are below the detection limit. Thus, the measured values of the water equiva- lent hydrogen indicate that ellipses 7 and 10 have highest priority with respect to this feature. However, we note that these estimates are based on the LEND measurements with a spatial resolution of $10 \mathrm{~km}$ and the ice concentration in regolith within this pixel may strongly vary. Therefore, a priority order of the ellipses with respect to a WEH parameter has undoubtedly a probabilistic rather than an absolute character. In the following stage of study, it is necessary to range the ellipses by their engineering features and to characterize their geological structure.

\section{GEOLOGICAL AND GEOMORPHOLOGICAL ANALYSIS OF THE LANDING ELLIPSES}

The geological and geomorphological description of the landing ellipses includes the analysis of the inclinations according to the LOLA and NAC data, rock content based on the Diviner data, crater statistics and crater density, as well as the geological structure based on the LOLA and LROC data.

\section{Surface Inclinations in the Landing Ellipses}

The percentage ratio of the different categories of the surface inclinations $\left(<7^{\circ}, 7^{\circ}-10^{\circ}, 10^{\circ}-15^{\circ}, 15^{\circ}-\right.$ $20^{\circ}$ and $>20^{\circ}$ ) (Krasilnikov et al., 2018) was calculated according to the LOLA data with the resolution of $60 \mathrm{~m} / \mathrm{px}$. The largest concentration of critical inclinations $\left(>10^{\circ}\right)$ is observed in ellipses 7,10 , and 11 , while the plain topography, in ellipses 2,3 , and 5 . To determine the inclinations at the base of a lander footpad span of $\sim 3.5 \mathrm{~m}$, additional studies are required based on determining the share of the shaded surface area in the NAC images with respect to the solar elevation (Abdrakhimov et al., 2015). This method was used for determining the inclinations at the base of the lander module in the primary $(1,4$, and 6$)$ and secondary (B-1, -2) landing ellipses in (Krasilnikov et al., 2018). Comparing the results obtained to the previous research using the LOLA database (Djachkova et al., 2017), we can see the difference in the inclinations $<7^{\circ}$ in several percent, which is likely related to the different methods of data processing.

In comparing the results of estimating the inclinations obtained by the NAC and LOLA images for ellipses 1, 4, 6 and B-1, 2, we recorded a noticeable increase in the inclinations greater than $10^{\circ}$ during the calculation by the shadow method (Krasilnikov et al., 2018). This is an expected result related to the fact that in using the $0.5-1 \mathrm{~m} / \mathrm{px}$ images, the shadow method leads to estimating the distribution of inclinations at the base of a few meters, and in the map with a spatial resolution of $60 \mathrm{~m} / \mathrm{px}$, these inclinations at the small base are smoothed and the probability of a hazardous slope is underestimated (Table 1). 


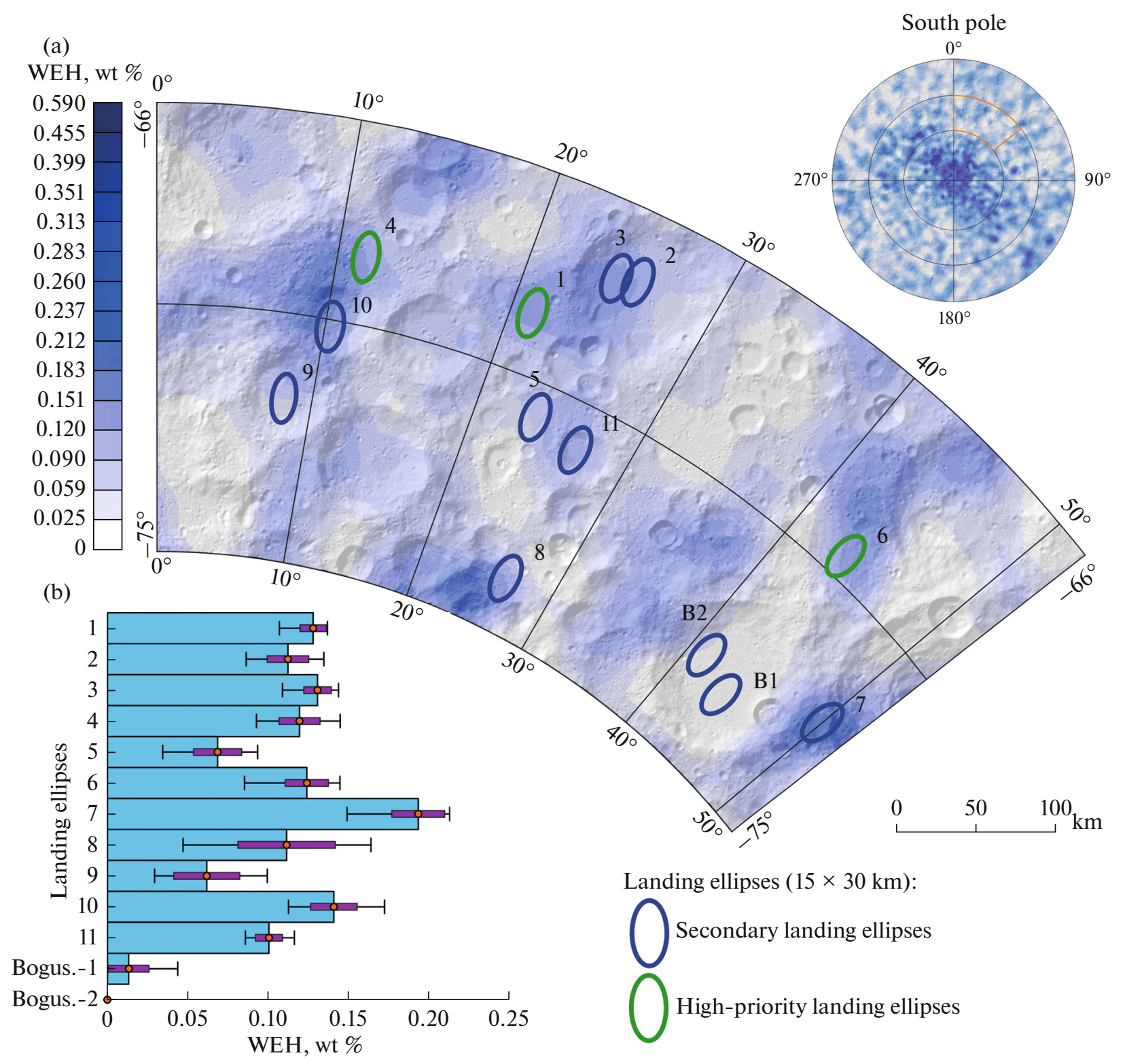

Fig. 2. (a) Map of values of water equivalent hydrogen (WEH) in the sector of Luna-Glob expedition operation according to (Sanin et al., 2017). Landing ellipses are shown; the insert depicts variations in the average WEH values for each ellipse. (b) Averaged WEH values for landing ellipses with $1 \sigma$ and dispersion.

\section{Analysis of Rock Content on the Surface}

No significant concentration of rocks was detected within the ellipses studied. The analysis of rock content was carried out using a Diviner thermal infrared radiometer and by analyzing the high-resolution LROC NAC images. The radiometer data are used to measure thermal inertia of the surface, which, in turn, makes it possible to estimate the model concentration of the rocks. In the Diviner experiment, the rocks are considered to be the objects on the surface with thermal inertia at least $1570 \mathrm{~J} \mathrm{~m}^{-2} \mathrm{~K}^{-1} \mathrm{~s}^{-1 / 2}$ at $200 \mathrm{~K}$, and the results of determining a degree of rock content (a share of area covered by rock fragments) are presented for the pixel size $\sim 237 \mathrm{~m}$ (Bandfield et al., 2011).

All ellipses demonstrated low values of the total content of rocks on the surface. The rock distribution has a fragmentary character, the increase in the number of rocks is observed in the fresh small craters (100$1000 \mathrm{~m}$ ); therefore, it makes sense to consider the maximum rather than average values of rock content in this work (Fig. 3). Most of the ellipses showed the low values of the maximum content of rocks, not exceeding $\sim 0.02 \%$ of rocks of the entire pixel surface area. A slight increase in the maximum content of 
Table 1. Distribution of the inclinations by the categories for primary and secondary landing ellipses. A share of the inclinations according to the LROC NAC data was calculated only for ellipses 1, 4, 6 and B1, B2 in Krasilnikov et al. (2018) and Abdrakhimov et al. (2015), respectively

\begin{tabular}{|c|c|c|c|c|c|c|c|c|}
\hline \multirow{2}{*}{$\begin{array}{l}\text { Ellipse } \\
\text { number }\end{array}$} & \multicolumn{7}{|c|}{ Data according to LOLA } & \multirow{2}{*}{$\begin{array}{l}\text { Data according } \\
\text { to LROC NAC } \\
\text { share of surface } \\
\text { with inclination } \\
\quad>10^{\circ}\end{array}$} \\
\hline & $\begin{array}{c}\text { average value } \\
\text { of inclinations, } \\
\text { degrees }\end{array}$ & $<7^{\circ}$ & $7^{\circ}-10^{\circ}$ & $10^{\circ}-15^{\circ}$ & $15^{\circ}-20^{\circ}$ & $>20^{\circ}$ & $\begin{array}{c}\text { share of surface } \\
\text { with inclination } \\
\quad>10^{\circ}\end{array}$ & \\
\hline 1 & 3.57 & 89.69 & 7.36 & 3.19 & 0.72 & 0.24 & 4.15 & 26 \\
\hline 2 & 2.99 & 92.89 & 4.55 & 2.91 & 1.40 & 0.40 & 4.71 & - \\
\hline 3 & 2.72 & 95.00 & 4.44 & 2.14 & 0.42 & 0.10 & 2.66 & - \\
\hline 4 & 4.03 & 86.03 & 8.91 & 4.74 & 1.50 & 0.11 & 6.34 & 23 \\
\hline 5 & 3.78 & 86.47 & 8.33 & 3.84 & 0.87 & 0.49 & 5.20 & - \\
\hline 6 & 4.62 & 83.23 & 12.19 & 5.00 & 0.27 & 0.00 & 5.28 & 17 \\
\hline 7 & 8.77 & 51.31 & 18.69 & 11.50 & 6.96 & 10.68 & 29.13 & - \\
\hline 8 & 5.11 & 77.20 & 15.24 & 4.65 & 0.49 & 0.69 & 5.83 & - \\
\hline 9 & 4.67 & 79.11 & 10.22 & 7.51 & 2.02 & 0.55 & 10.07 & - \\
\hline 10 & 7.98 & 55.75 & 12.77 & 16.03 & 11.38 & 4.40 & 31.81 & - \\
\hline 11 & 8.75 & 41.89 & 16.96 & 24.89 & 14.79 & 1.33 & 41.01 & - \\
\hline B1 & 2.9 & 92.38 & 4.02 & 1.78 & 0.35 & 0.04 & 2.17 & 15 \\
\hline B2 & 2.62 & 93.98 & 3.80 & 0.88 & 0.09 & 0.01 & 0.98 & 18 \\
\hline
\end{tabular}

rocks on the surface was recorded for ellipses 2 $(0.036 \%), 3(0.028 \%)$, and B2 $(0.05 \%)$.

The regions of rock distribution were studied using the high-resolution NAC images with the maximum resolution of $0.5 \mathrm{~m} / \mathrm{px}$. The regions where the high values of rock content are recorded according to the Diviner data (Fig. 4, A1, B1) are characterized by the spread rocks (Fig. 4, A2, B2). Most of the rocks are up to $2 \mathrm{~m}$ in diameter; however, some rocks reach $5 \mathrm{~m}$ across. Demidov and Basilevsky established in (2014) that the typical average ratio of the height $(h)$ to the diameter of the rocks $(d)$ is about 0.5 for the Moon; consequently, the average value of the rock height in the craters considered (Fig. 4) reaches $1 \mathrm{~m}$, and the maximum height approaches $2.5 \mathrm{~m}$. Together with the
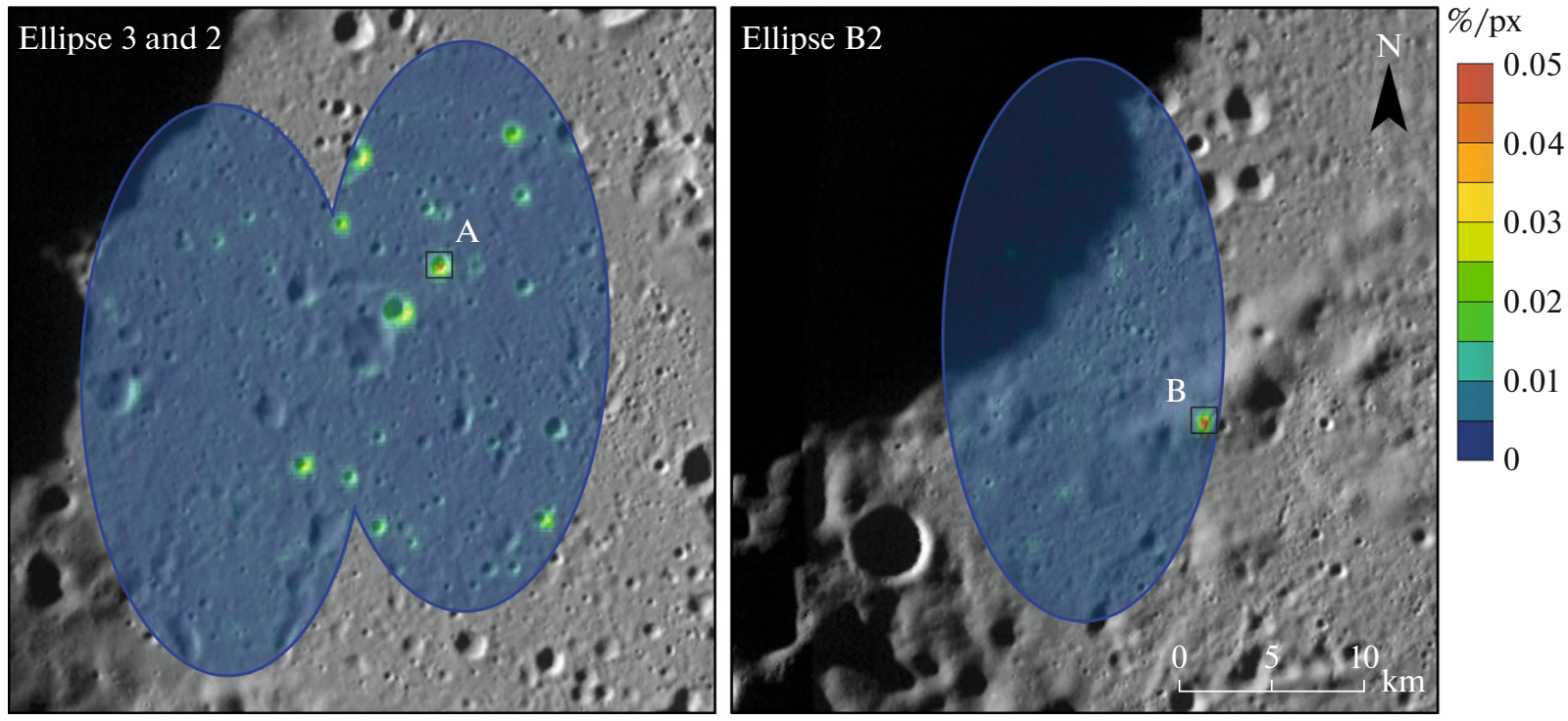

Fig. 3. Analysis of rock content on the surface using a Diviner thermal infrared radiometer. Ellipses with the greatest percentage of surface occupied by rocks (up to $0.05 \%$ ) per one pixel area $\left(237 \mathrm{~m}^{2}\right)$ are shown. 

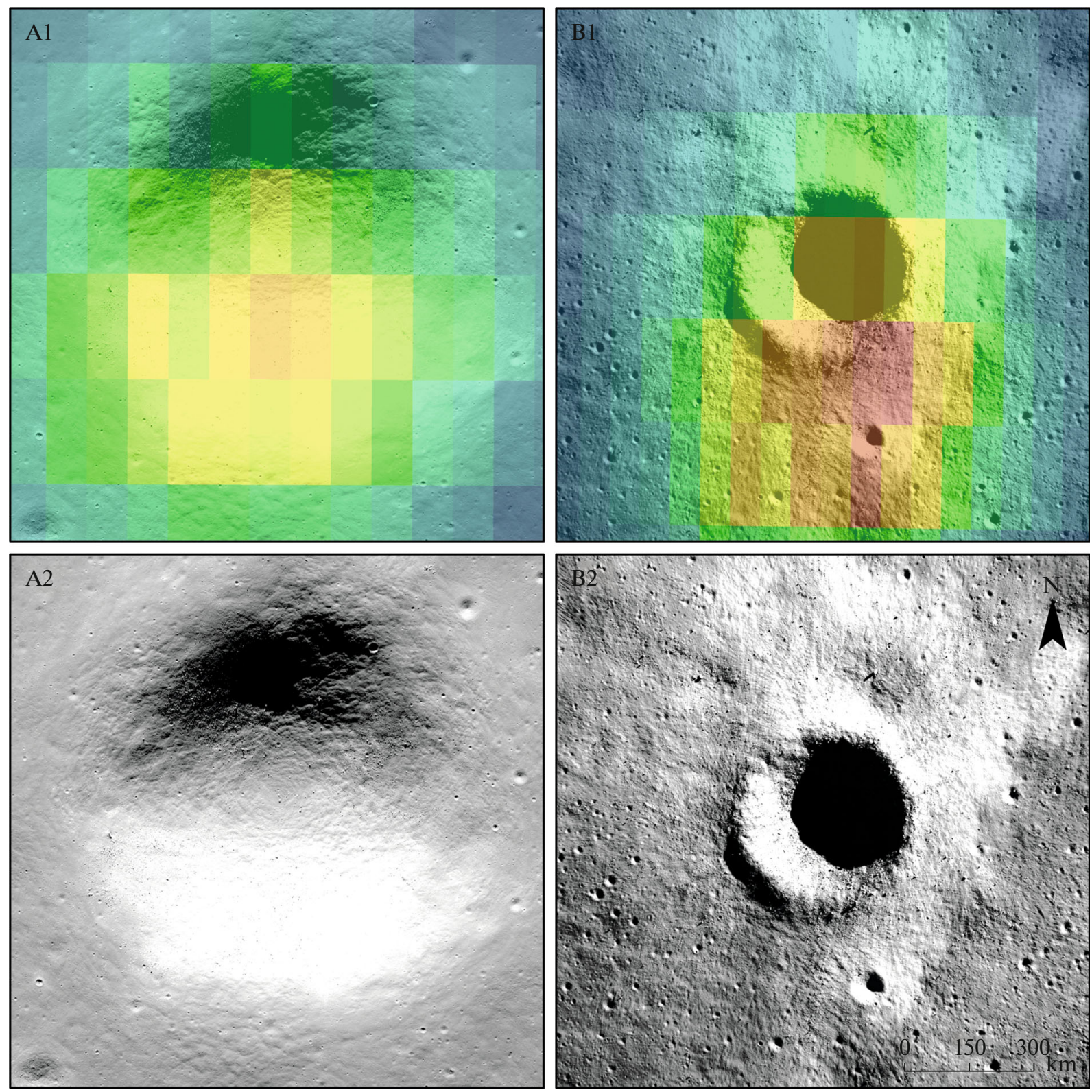

Fig. 4. NAC images (A2, B2), showing the regions with high contents of rocks according to the Diviner data (A1, B1). Location of $\mathrm{A}$ and $\mathrm{B}$ segments is illustrated in Fig. 3.

inclinations at $>10^{\circ}$ on the walls, such craters would create a considerable threat to spacecraft landing. However, a spacecraft is highly unlikely to land in such a crater, the landing possibility does not exceed 2.7, 0.6 , and $0.3 \%$ for ellipses 2,3 , and B-2, respectively, with the highest contents of rocks. For the other ellipses, it is even less likely that the spacecraft will encounter big rocks.

\section{Crater Statistics and Density of Craters}

The terrain age was determined using crater statistics. Different approaches were used in analyzing crater statistics with respect to the crater diameter. The craters $>1 \mathrm{~km}$ in diameter without clearly marked ejecta are depicted in the geological and geomorphological maps of the landing ellipses along the boundary of the distinguished rim. The craters with markedly expressed ejecta form separate geomorphological units " $c$ " (the geomorphological units are described in the following section). The craters $100-1000 \mathrm{~m}$ in diameter are not mapped; however, they are included into the description of geomorphological units that indicates their low $\left(0.6\right.$ craters per $\left.1 \mathrm{~km}^{2}\right)$, medium $\left(0.72\right.$ per $\left.1 \mathrm{~km}^{2}\right)$, and high $\left(1.03\right.$ per $\left.1 \mathrm{~km}^{2}\right)$ density. For geological and geomorphological units, the density of small craters 3-100 $\mathrm{m}$ in diameter was calculated. The 
Table 2. Number of small craters in geological and geomorphological units

\begin{tabular}{c|c|c|c|c}
\hline \multirow{2}{*}{ Geomorphological unit } & \multicolumn{4}{|c}{ Number of small craters per $0.1 \mathrm{~km}^{2}$ in units of a different age } \\
\cline { 2 - 5 } & $\mathrm{pN}$ & $\mathrm{N}$ & $\mathrm{I}$ & $\mathrm{E}$ \\
\hline $\mathrm{p}$ & 770 & - & 860 & - \\
$\mathrm{pc}$ & 653,579 & - & 679 & 742 \\
$\mathrm{rp}$ & 631 & 644 & 698 & - \\
$\mathrm{sh}$ & 682 & - & 379,695 & 689 \\
$\mathrm{~h}$ & - & - & 594 & - \\
\hline
\end{tabular}

density was estimated at the segments of $0.125 \mathrm{~km}^{2}$ and recalculated to the density per $0.1 \mathrm{~km}^{2}$. The number of small craters has a weak correlation with the surface age and depends primarily on the terrain topography (Table 2). For example, the greatest number of small craters can be encountered within the gently undulating plain surface "p." With an increase in the surface inclinations on hills " $h$ " and gently sloping hills "sh," the density of the small craters decreases evidently because of their destruction when regolith moves along the slopes.

\section{Surface Geology}

The main transformation of the surface within the studied ellipses occurred during the formation of South Pole-Aitken basin (SPA) and the large impact structures of pre-Nectarian $(\mathrm{pN})$, Nectarian $(\mathrm{N})$ and Imbrian (I) ages. The thickness of ejecta from the impact craters in the study region was calculated in (Ivanov et al., 2018): SPA, $3.18 \pm 0.96 \mathrm{~km}(96 \%) ; \mathrm{pN}$, $0.10 \pm 0.03 \mathrm{~km}(2.9 \%) ; \mathrm{N}, 0.02 \pm 0.00 \mathrm{~km}(0.7 \%) ; \mathrm{I}$, $0.01 \pm 0.00 \mathrm{~km}(0.4 \%)$. The impact events which led to the formation of pre-Nectarian Boguslawsky, Boussingault, Manzinus, and Simpelius craters ( $\mathrm{pN}$ age), Nectarian Boussingault A (N) crater and Imbrian Moretus and Schomberger (I) craters also exerted a significant influence on the study terrain due to secondary cratering and overlapping of the surface by ejecta. One of the most important geological problems was to determine the probability of encountering ancient pre-Nectarian material covered by the SPA on the surface of the study ellipses. These rocks could have reached the surface due to material excavation as a result jf penetration through the SPA ejecta. The excavation depth was estimated for all potential material sources around the study ellipses based on the cratering model according to Melosh (1989) and assuming $1 / 10$ of the crater depth to the diameter. To calculate the thickness of the SPA basin ejecta, the model according to House et al. (1983) was used. The models according to Melosh (1989) and Housen et al. (1983) showed that most of the craters with ejecta located in the study ellipses pierced the SPA cover.

For each ellipse, the thickness of ejecta overlapping their surface was estimated. Depending on a type and size of the crater, the models according to Sharpton (2014) or Housen et al. (1983) were used for the craters up to or greater than $45 \mathrm{~km}$ in diameter, respectively. In addition to the model estimation, the assumed boundaries of the ejecta underwent topographic profiling, which showed inconsistency in some cases between the model ejecta thickness and the measured difference in the elevations of the surrounding surface and the ejecta. This is related to the fact that the upper portions of the ejecta cover do not completely determine the topography observed but overlay the underlying surface and are mixed with underlying regolith.

The photogeological analysis of the NAC, WAC images and the topographic analysis of the DTM allowed us to compare the detailed geological and geomorphological maps of the study ellipses in scale $1: 100000$. The stratigraphy of the morphological units shown in the maps was identified using the regional geological maps of the lunar southern polar region (Wilhelms and McCauley, 1979; Ivanov et al., 2018).

In the maps of the ellipses, a stratigraphic age is designated by color and capital letters, a morphological surface type is shown in small letters (Figs. 6 and 7-13). They include the following indices: " $p$ ", a gently undulating plain surface with low density of craters and slopes $<10^{\circ}$; " $p c$ ", a gently undulating cratered plain with an average or high density of small (1001000 m) craters; "rp", a knob-and-basin plain with low or average crater density; "sh", gently sloping hills, with an insignificant difference in elevation and low or average density of craters; " $h$ ", hills with slopes to $20^{\circ}$ and a difference in elevation to $\sim 300 \mathrm{~m}$ with low crater density; "s", slopes of craters with landslides or overlapped by the subsequent ejecta; "c", craters of an average size (from one to several kilometers in diameter), for which the ejecta zone can be distinguished; "sc", chains and fields of secondary craters; "cl", landslides primarily on the crater slopes; "osc", partly overlapped chains and fields of secondary craters; index "i" designates geomorphological units composed of ejecta from the impact craters (Figs. 5 and 6-12).

In this work, we did not consider the geological and geomorphological structure of primary landing ellipses 1, 4, and 6, or ellipses in Boguslawsky crater described in (Ivanov et al., 2015, 2018). 


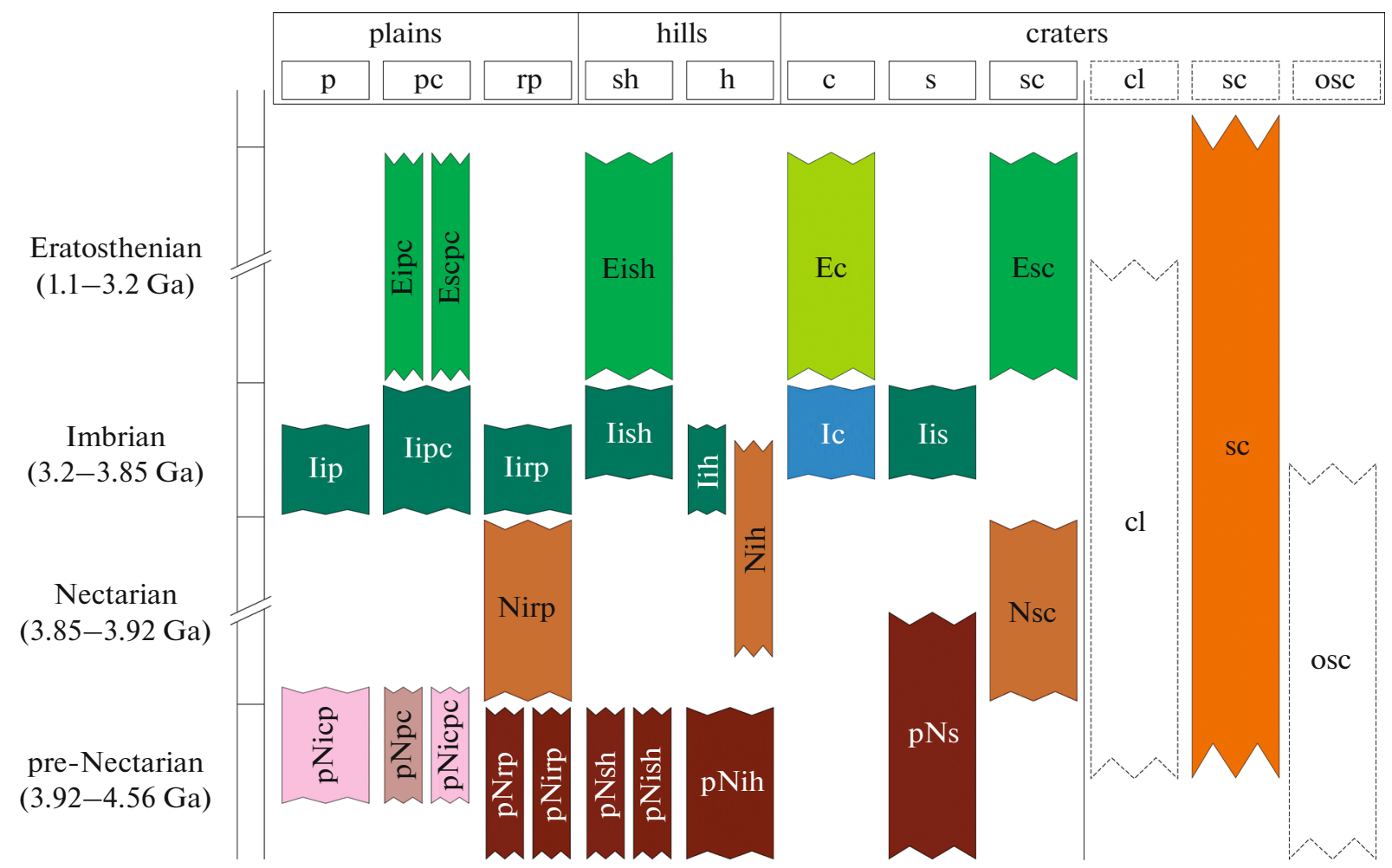

Fig. 5. Correlation pattern of compositional complexes depicted in geological and geomorphological maps for the landing ellipses.
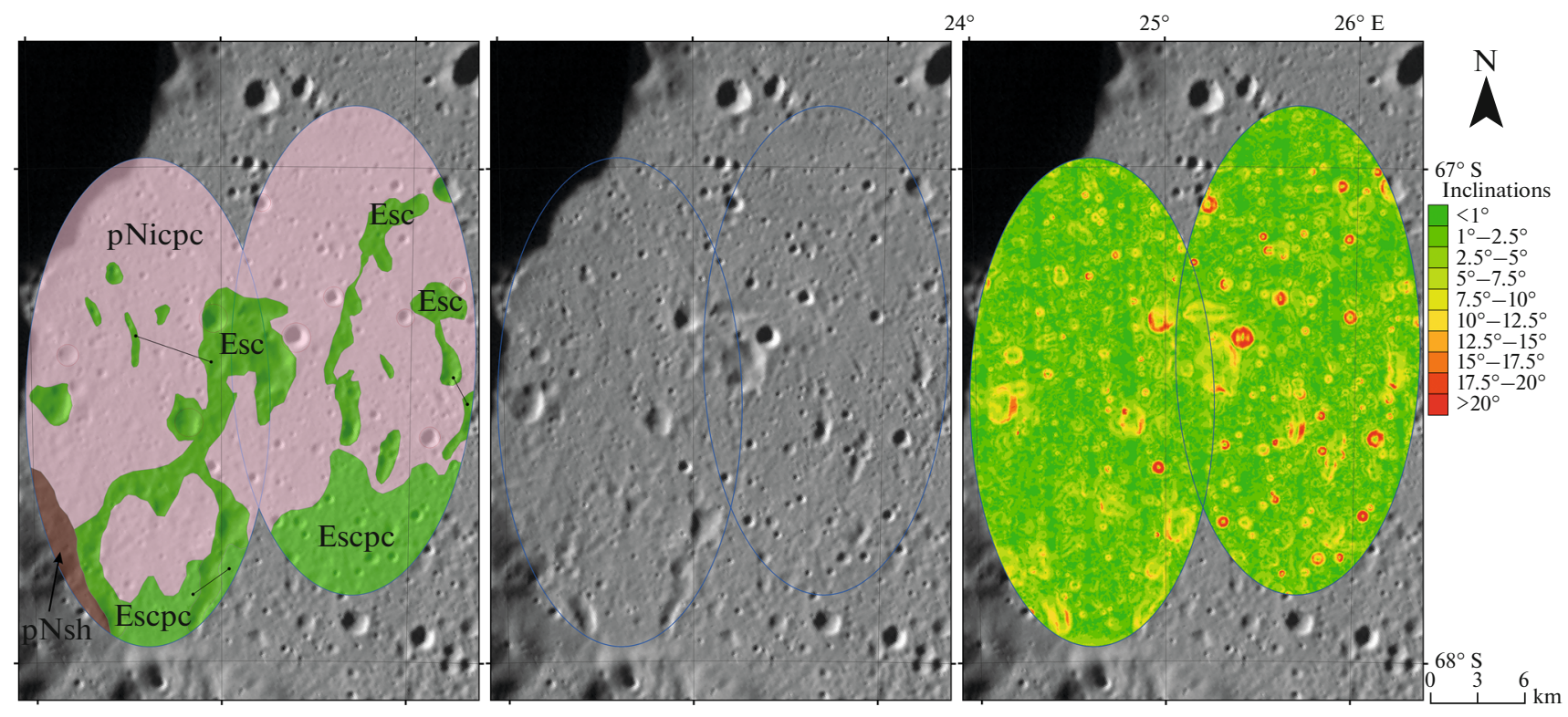

Fig. 6. Landing ellipses 2 and 3.

Ellipses 2 and $3\left(67.48^{\circ} \mathrm{S}, 24.61^{\circ} \mathrm{E}\right.$ and $67.37^{\circ} \mathrm{S}$, $24.70^{\circ} \mathrm{E}$, respectively) are located on the Manzinus crater floor (Fig. 6). The total difference in elevation within ellipse 2 is $\sim 100 \mathrm{~m}$, and the degree of the surface inclination to the north is $\sim 0.19^{\circ}$. The difference in elevation within ellipse 3 is $\sim 80 \mathrm{~m}$ with the degree of the surface inclination to the north at $\sim 0.21^{\circ}$. These ellipses are characterized by an insignificant increase in the rock content in several Eratosthenian-Copernicus craters. Most of the inclinations at $>10^{\circ}$ belong to these craters ( $\sim 1-2 \mathrm{~km}$ in diameter). Four main geomorphological units were distinguished within ellipses 2 and 3. 

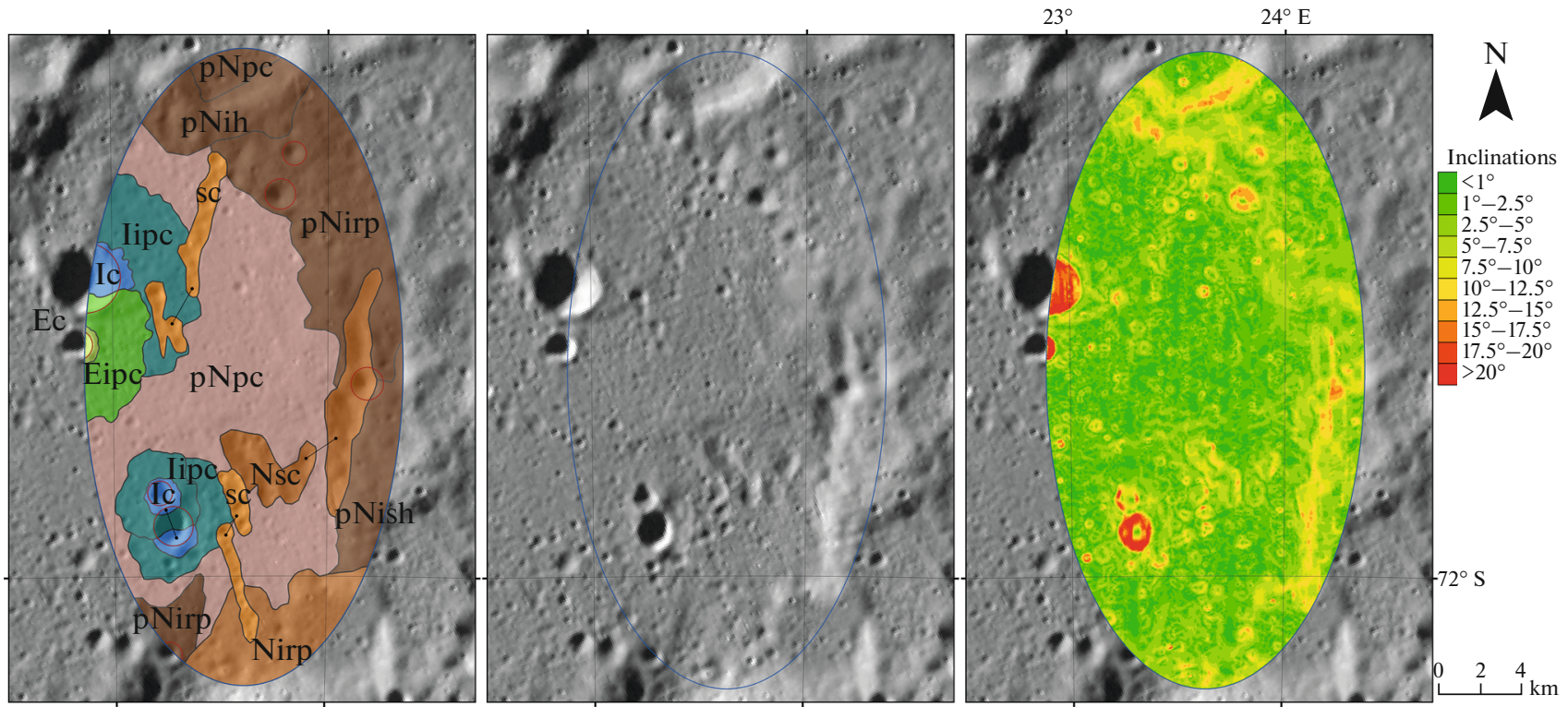

Fig. 7. Landing ellipse 5.
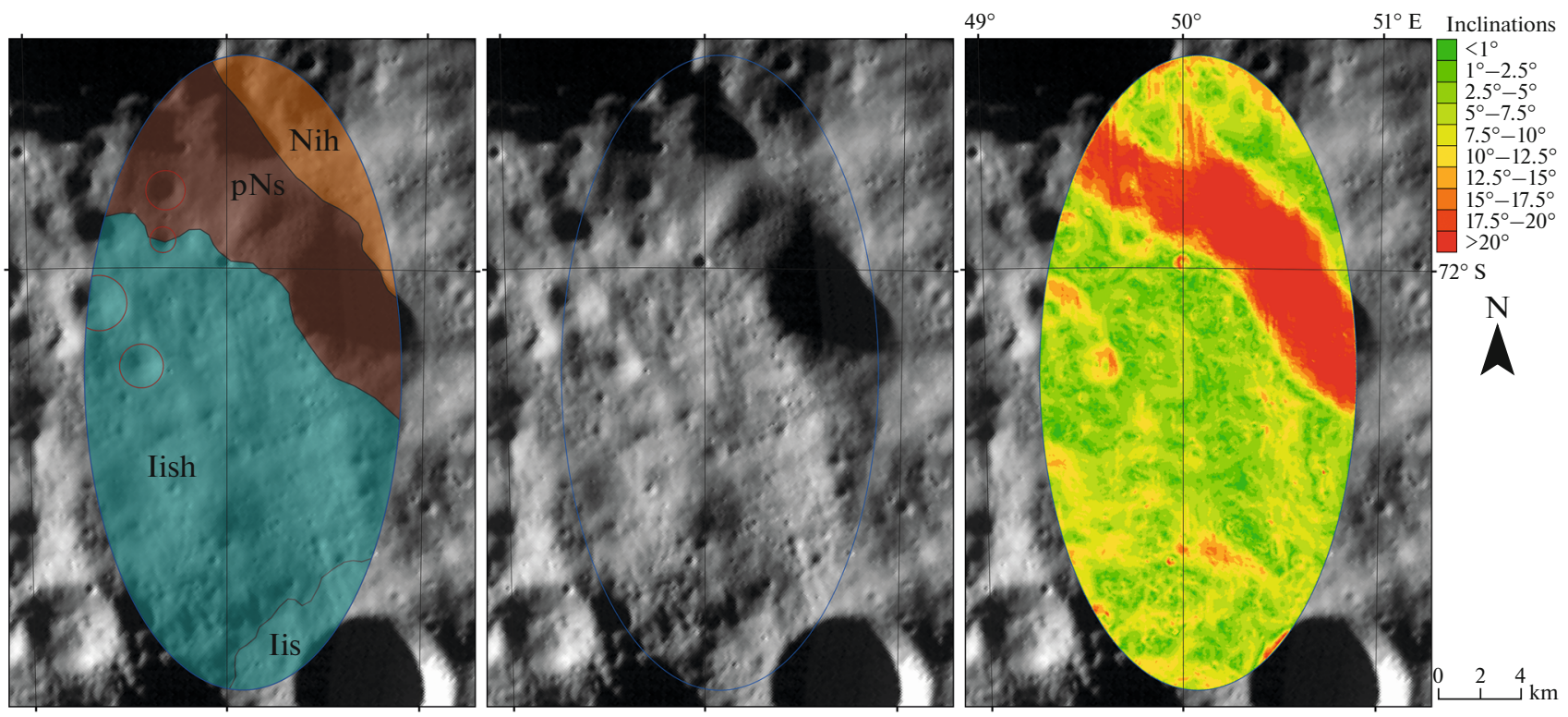

Fig. 8. Landing ellipse 7.

Unit pc (pNicpc) occupies $69.1 \%$ of the terrain of both ellipses and represents a gently undulating cratered surface with primarily small craters (up to $500 \mathrm{~m}$ ) located on the floor of large pre-Nectarian Manzinus crater (96 km in diameter). Manzinus crater is rather big in size for being able to penetrate through the SPA ejecta, which means that the ancient pre-Nectarian material preceding SPA was likely to occur in unit pNicpc. Unit sc (Esc) occupies $17.7 \%$ of both ellipses and represents elongated depressions or chains of secondary craters formed by ejecta from Eratosthenian Manzinus E crater $\left(68.98^{\circ} \mathrm{S}, 24.72^{\circ} \mathrm{E}, 18 \mathrm{~km}\right.$ in diameter). Ejecta from Manzinus E crater also form unit pc (Escpc), a cratered gently undulating plain in the south of the ellipses (11.4\% of two ellipses). The Manzinus E ejecta thickness within the ellipses does not exceed a few meters. The interior slope of Manzinus crater forms a unit of gently sloping hills $\mathrm{h}$ (pNsh) in the southwestern part of ellipse 3 and occupies $1.8 \%$ of the entire terrain.

Within ellipse $5\left(70.68^{\circ} \mathrm{S}, 23.63^{\circ} \mathrm{E}\right), 12$ geologicalgeomorphological units were identified (Fig. 7). Inclinations of $>15^{\circ}$ are confined to comparatively young Imbrian and Eratosthenian craters. A major part of the 

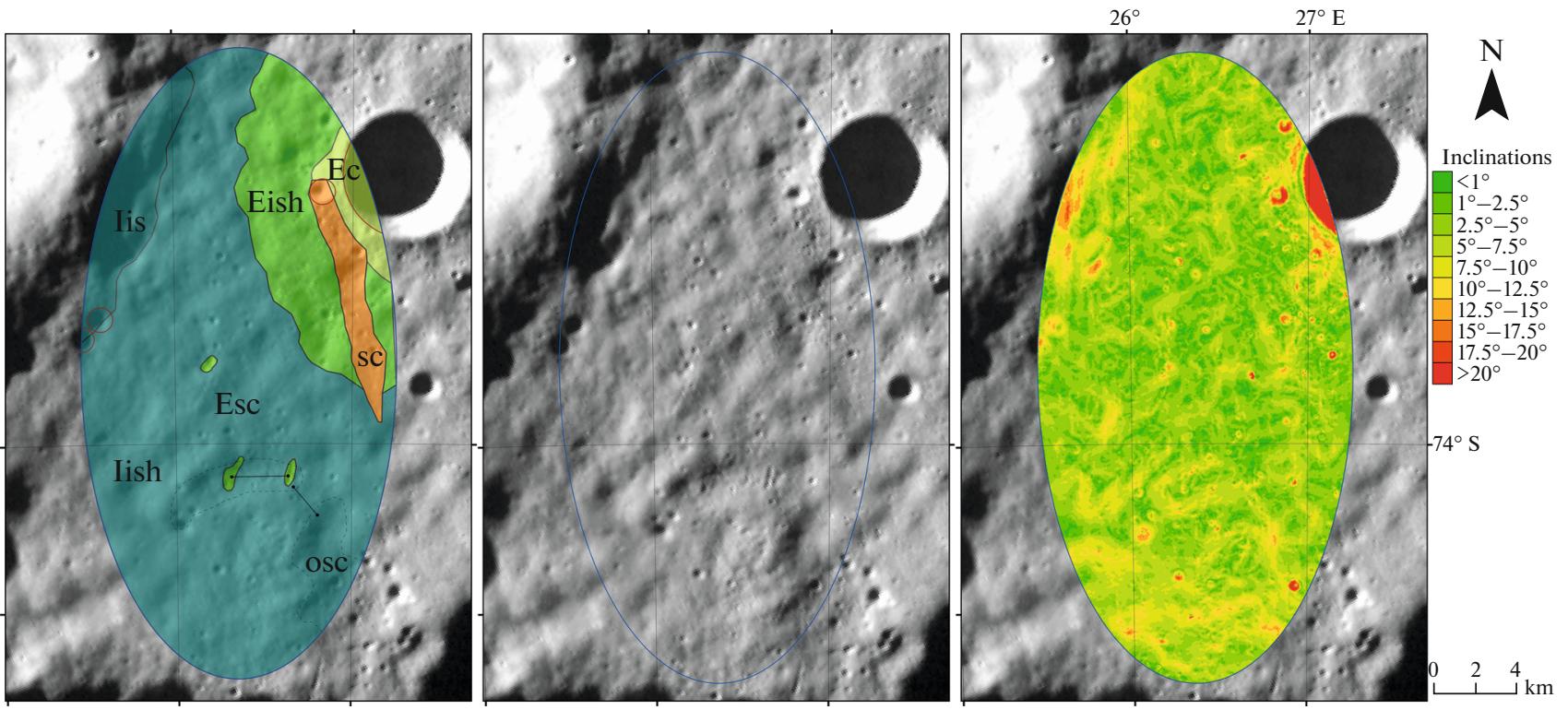

Fig. 9. Landing ellipse 8.
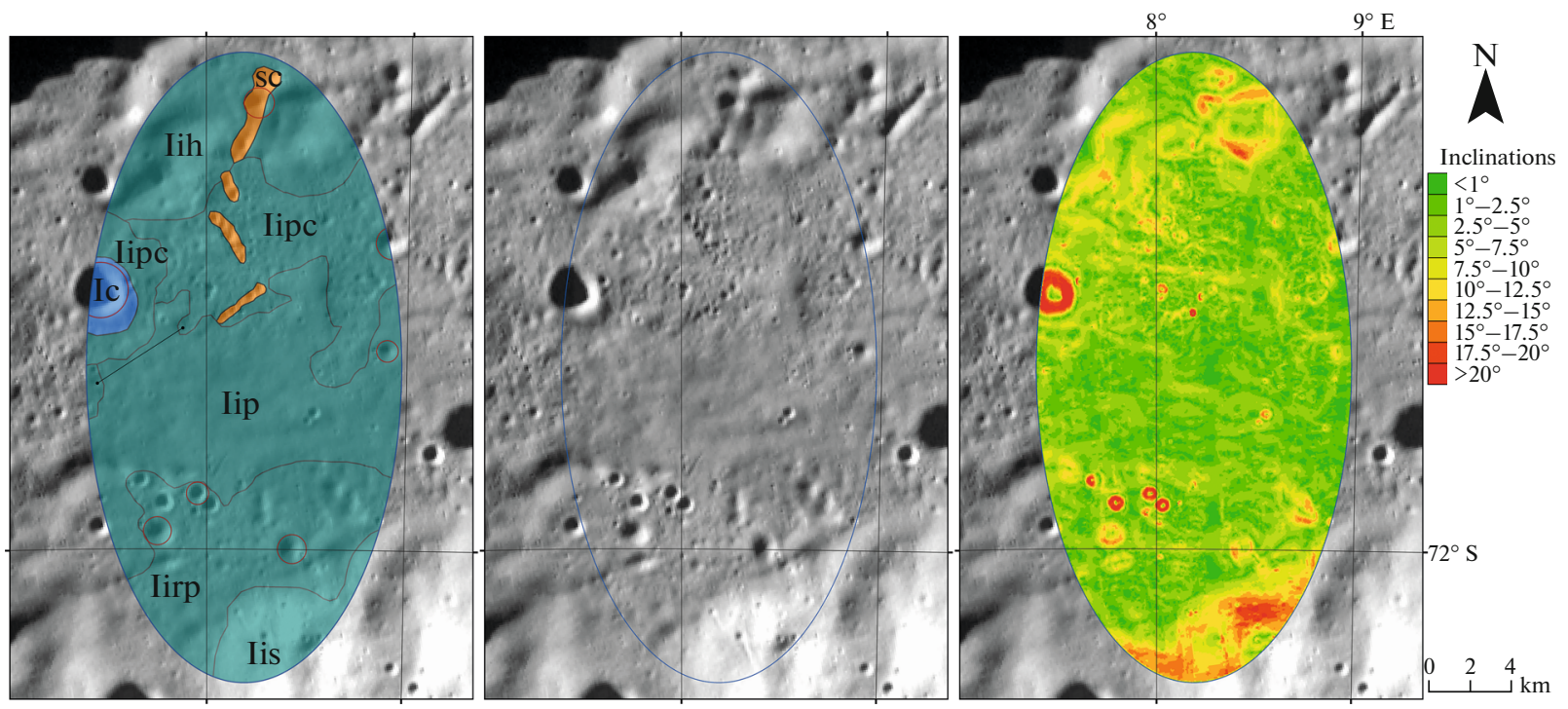

Fig. 10. Landing ellipse 9.

surface is pre-Nectarian and represents unit pc $(\mathrm{pNpc})$, a cratered plain that occupies $36.2 \%$ of the terrain. In the eastern and northeastern part of the ellipse there are ejecta from Boguslawsky C crater $(\mathrm{pN})\left(70.99^{\circ} \mathrm{S}, 27.7^{\circ} \mathrm{E}, 34 \mathrm{~km}\right.$ in diameter) with different types of topography: $5 \%$ of sh (pNish) and rp (pNirp). This crater is the only possible source of preNectarian material for this ellipse that preceded SPA. This material can be found in the prospective ejecta of Boguslawsky $\mathrm{C}$ crater and on plain $\mathrm{pNpc}$. The terrane with rp (pNirp) type of topography is found in the southwestern part of the ellipse and belongs to Simpelius $\mathrm{G}$ crater $\left(71.78^{\circ} \mathrm{S}, 22.76^{\circ} \mathrm{E}, 22 \mathrm{~km}\right.$ in diameter $)$.
The total area of these units is $17.7 \%$ of the ellipse surface. The northern part of the ellipse comprises ejecta from Manzinus $\mathrm{C}$ crater $\left(\mathrm{pN}, 69.99^{\circ} \mathrm{S}, 21.68^{\circ} \mathrm{E}\right.$, $24 \mathrm{~km}$ in diameter), forming two geomorphological units: cratered plain pc (pNipc) in 1.7\% of the ellipse area and elongated ridge $h$ in $5.7 \%$ of the ellipse area. In the south of the ellipse, there is knob-and-basin plain rp (Nirp) in $6.9 \%$ of the Nectarian ellipse that belongs to the Simpelius $G$ crater ejecta. Slightly northward, this crater formed elongated depressions and a chain of secondary craters sc (Nsc) in $6.5 \%$ of the ellipse area. Ellipse 5 includes a few average-sized craters of Imbrian and Eratosthenian ages. Their geo- 

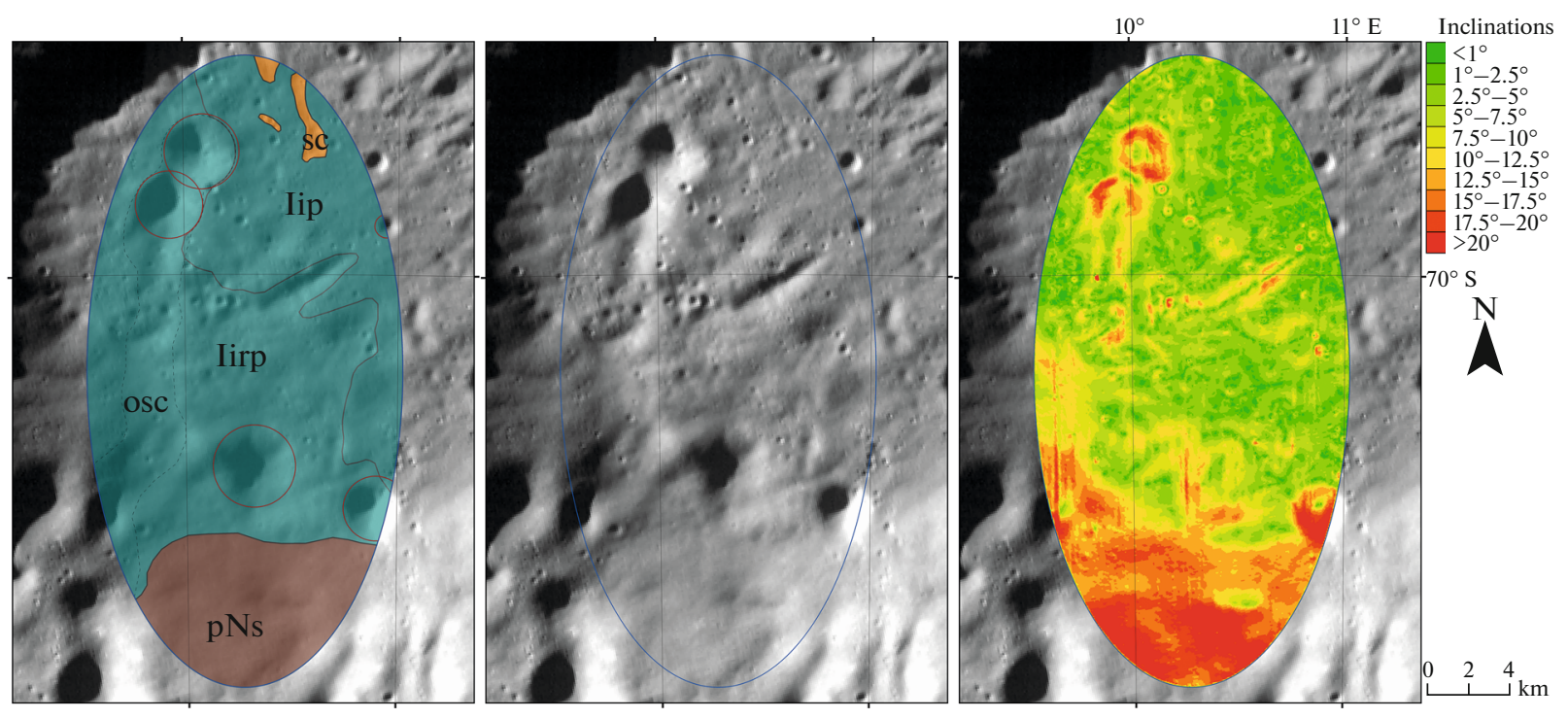

Fig. 11. Landing ellipse 10.
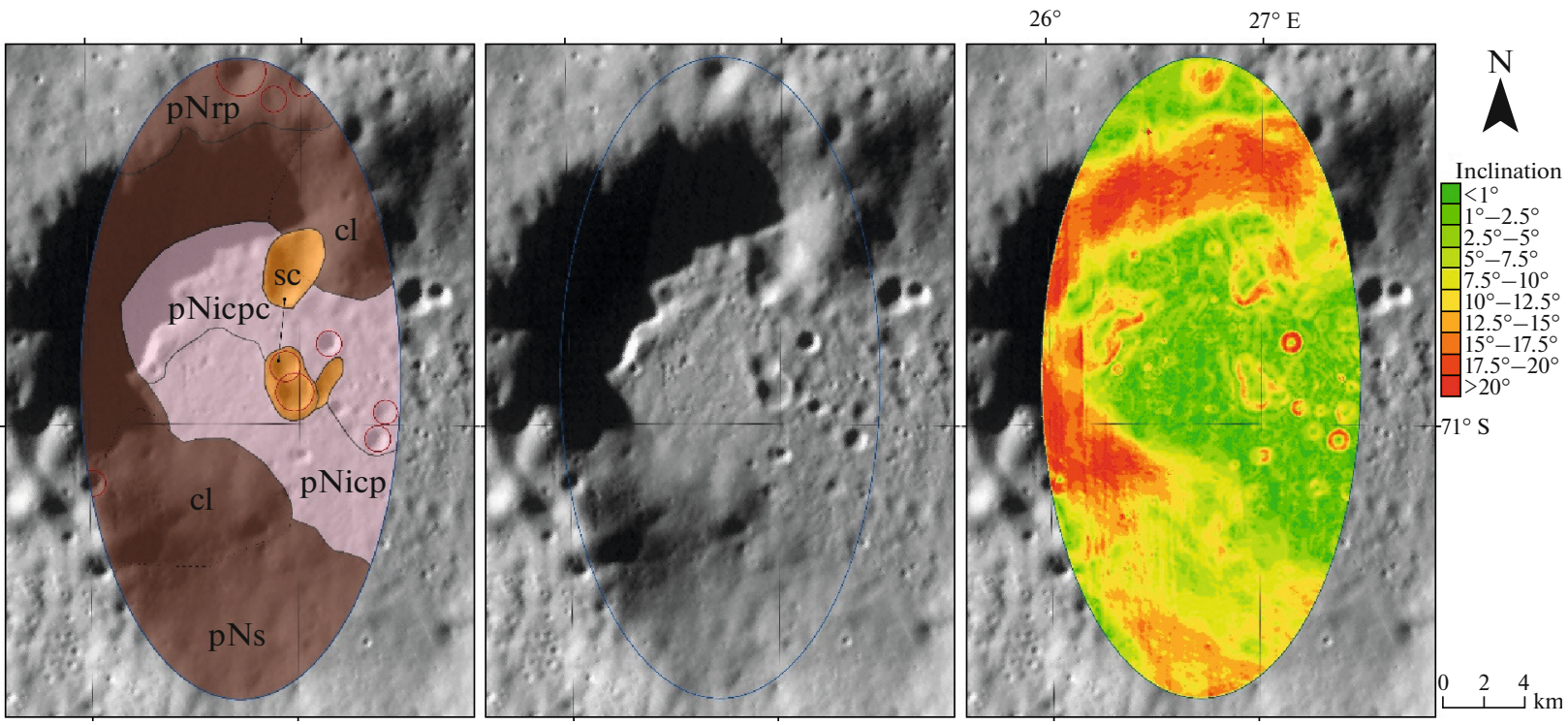

Fig. 12. Landing ellipse 11.

morphological units represent a crater bowl itself and a cratered plain of ejecta around them, pc. The Imbrian units occupy $2.3 \%$ (Ic) and $11.2 \%$ (Iipc) of the ellipse area, while the parts of the Eratosthenianaged crater in the west of the ellipse cover $0.3 \%$ (Ec) and $4 \%$ (Eipc) of the ellipse area. A share of the chains of the secondary craters sc is $4.5 \%$ for this ellipse; the chains are oriented primarily north-south.

Ellipse $7\left(72.16^{\circ} \mathrm{S}, 50.09^{\circ} \mathrm{E}\right)$ is located between Boguslawsky and Boussingault craters (Fig. 8). Most part of the surface $(61.3 \%)$ is taken by unit sh (Iish) with the difference in elevations up to $\sim 500 \mathrm{~m}$. This unit was formed by ejecta from the comparatively young (Imbrian-aged) Boguslawsky D crater $\left(72.86^{\circ} \mathrm{S}\right.$, $47.41^{\circ} \mathrm{E}, 22 \mathrm{~km}$ in diameter); the model thickness of ejecta within the crater reaches a few tens of meters. The crater located in the southeast of the ellipse is also Imbrian (I)-aged, its external part of the rim (Iis) covers $4.8 \%$ of the ellipse terrain area, the crater diameter is $8 \mathrm{~km}$. In the north of the ellipse lies interior slope s of Boussingault crater $\left(70.21^{\circ} \mathrm{S}, 53.73^{\circ} \mathrm{E}, 128 \mathrm{~km}\right.$ in diameter) of pre-Nectarian age ( $\mathrm{pNs}$ ) with exposure to the northeast. The slope has a $\sim 1900$-m difference in elevations with an average inclination of $\sim 18^{\circ}$. Inside Boussingault crater lies younger Boussingault A crater $\left(69.96^{\circ} \mathrm{S}, 53.87^{\circ} \mathrm{E}, 75 \mathrm{~km}\right.$ in diameter) of Nec- 
tarian age. Its ejecta overlapped the floor and the slopes of Boussingault crater; however, the Nectarianaged material of these ejecta assumedly displaced in part along the steep slope of Boussingault crater, uncovering the Boussingault slope of the pre-Nectarian age. Thus, in the northeast of the ellipse, hills $h$ formed of ejecta from Boussingault A (Nih) crater, occupying $8.4 \%$ of the ellipse area, with assumed thickness of the deposits equal to more than a hundred meters. The more ancient material than SPA ejecta may be encountered in this crater ejecta.

Ellipse $8\left(73.882^{\circ} \mathrm{S}, 26.363^{\circ} \mathrm{E}\right)$ is located in the plain with a slight tilt to the north (Fig. 9). The difference in elevations between the northern and southern parts of the ellipse is $\sim 250 \mathrm{~m}$, which corresponds to the degree of the surface inclination at $\sim 0.8^{\circ}$ within the ellipse. The surface inside the ellipse is overlapped by the material ejecta from Schomberger (I) crater with a thickness from $\sim 100 \mathrm{~m}$ in the southern part of the ellipse to $\sim 40 \mathrm{~m}$ in the northern part. The most part of the ellipse $(70.7 \%)$ is located on the gently sloping hummocky surface sh (Iish) with an average density of craters. The ejecta from Schomberger crater, overlapping the most part of the ellipse, are highly likely to contain material ejected from under the SPA cover. In the northwest of the ellipse, there is a slightly sloping external rim of Schomberger D crater $\left(\mathrm{pN}-\mathrm{N}, 73.38^{\circ} \mathrm{S}\right.$, $24.22^{\circ} \mathrm{E}, 24 \mathrm{~km}$ in diameter) overlapped by Imbrian $\mathrm{s}$ (Iis) deposits. This crater ejecta are covered by the Imbrian deposits and have a model thickness of $\sim 100 \mathrm{~m}$ in the northwestern part of the ellipse, decreasing to $\sim 10 \mathrm{~m}$ in the southeastern part. In the northeast of the ellipse, there is Schomberger $\mathrm{Z}$ crater of an Eratosthenian age $\left(73.59^{\circ} \mathrm{S}, 27.29^{\circ} \mathrm{E}, 6 \mathrm{~m}\right.$ in diameter) with a markedly expressed crater bowl (Ec, $2.9 \%$ of the ellipse area) and ejecta representing a gently sloping hummocky surface sh (Eish, $15 \%$ of the ellipse area). The ejecta thickness is a few tens of meters. The internal rim of the crater has high inclination values $>20^{\circ}$ at the base of $60 \mathrm{~m}$. The elongated depressions formed by secondary craters sc (Esc, $0.5 \%$ of the ellipse area) are encountered around the crater. Within the ellipse, there are also chains and hollows of the secondary craters overlapped by Imbrian ejecta osc, $4 \%$ of the ellipse area.

Ellipse $9\left(71.718^{\circ} \mathrm{S}, 8.186^{\circ} \mathrm{E}\right)$ lies on the floor of Simpelius D crater $(\mathrm{pN})$ at the boundary of the Imbrian ejecta from Moretus crater $\left(70.64^{\circ} \mathrm{S}, 354.05^{\circ} \mathrm{E}\right.$, $115 \mathrm{~km}$ in diameter). The model thickness of these ejecta is about $50 \mathrm{~m}$ (Fig. 10). The ejecta of this crater form different types of the surfaces, including smooth slightly sloping surface $\mathrm{p}$ (Iip, $31.7 \%$ of the ellipse area), gently undulating cratered surface pc (Iipc, $21.8 \%$ of the ellipse area), knob-and-basin surface rp (Iirp, $20.5 \%$ of the ellipse area) with numerous small (hundreds of meters in diameter) craters. The interior slope of Simpelius D crater (56 km in diameter) is partly overlapped by Imbrian deposits s (Iis, 6.3\% of the ellipse area). At the western boundary of the ellipse lies a crater c of an Imbrian age, $2.5 \mathrm{~km}$ in diameter (Ic, $1.9 \%$ of the ellipse surface) surrounded by ejecta rp. In the north of the ellipse, there is a hummocky surface $\mathrm{h}$ (Iih, $15.7 \%$ of the ellipse surface). In the northern part of the ellipse, there are also elongated depressions formed by secondary craters sc. Moretus crater can be a source of the ancient pre-Nectarian material ejected from under the SPA cover.

Ellipse $10\left(70.148^{\circ} \mathrm{S}, 10.288^{\circ} \mathrm{E}\right)$ is located $26 \mathrm{~km}$ northward from the previous ellipse on the floor of adjacent Simpelius E crater (43 km in diameter) with a thickness of $\sim 30 \mathrm{~m}$ (Fig. 11). The plain material of the Imbrian age, p (Iip, $25.7 \%$ of the ellipse area) and rp (Iirp, 56.4\% of the ellipse area), ejected from Moretus crater is also dominant in this ellipse. The interior slope of Simpelius E crater $(\mathrm{pN})$, which lies in the south of the study ellipse, has significant inclinations and is most unlikely overlapped by ejecta of an Imbrian age $\mathrm{s}$ (pNs, $16.7 \%$ of the ellipse area). In the north of the region lies a small cluster of secondary craters sc at $1.2 \%$ of the ellipse area. In the east of the ellipse, we identify the elongated depression, osc, overlapped by ejecta of an Imbrian age. Like in the previous ellipse, the material of Moretus crater is a possible source of the ancient pre-Nectarian material.

Ellipse $11\left(70.930^{\circ} \mathrm{S}, 26.715^{\circ} \mathrm{E}\right)$ lies on the floor of ancient Boguslawsky $\mathrm{C}$ crater (35 km in diameter) of a pre-Nectarian ( $\mathrm{pN}$ ) age (Fig. 12). The crater floor is occupied by a plain gently undulating surface $\mathrm{p}$ (pNicp, $14.5 \%$ of the ellipse area) and a strongly cratered gently undulating surface pc (pNicpc, $18.4 \%$ of the ellipse area). In the north and the southeast, there is a steep interior slope s (pNs, 33\% of the ellipse area) of Boguslawsky $\mathrm{C}$ crater, with a degree of the inclination of $>15^{\circ}$. The total difference in elevations of the crater interior slopes reaches $\sim 1200 \mathrm{~m}$. In the north of the ellipse, beyond the crater, there is a knob-andbasin plain rp (pNrp, 7.3\% of the ellipse area). On the interior slope, there are several large-volume landslides (cl $22.7 \%$ of the ellipse area). Within the crater boundary lie several series of secondary craters, sc ( $4.1 \%$ of the ellipse area). Boguslawsky $\mathrm{C}$ crater is a potential source of the ancient pre-Nectarian material, which is more ancient than the SPA cover.

The general character of the surface of the study ellipses is strongly affected by secondary cratering. In some ellipses, we identify the clusters of small (up to $1 \mathrm{~km}$ ) secondary craters and the elongated troughsthe traces of a tangent impact of ejected material. According to the results of studying the topography and the geological structure, the study ellipses can be divided into the high and low priority ones from the scientific point of view. In this case, scientific significance of the ellipses is determined not so much by the model contents of ice but by the other characteristics, e.g., by the variety of the sources of material accumulated at the potential sampling sites. The ellipses within which we can locate an ancient pre-Nectarian 
material ejected from under the SPA cover also have a significant role. Ellipses 2 and 3 are located in Manzinus crater, whose depth of excavation allowed throwing the material out of the SPA cover. Ellipse 5 consists primarily of pre-Nectarian units with different surface morphology; Nectarian, Imbrian, and Eratosthenian units, as well as clusters of secondary craters can also be encountered. In the east of the ellipse, there are deposits of Boguslawsky $\mathrm{C}$ crater that can be a source of material thrown out of the SPA cover. In the east of the ellipse, there are deposits of Boguslawsky C crater, that can be the source of material thrown out of the SPA cover. Ellipse 7 is of interest from the geological point of view in that the intercrater plain overlapped by the Imbrian ejecta is discontinued by the interior slope of the pre-Nectarian Boussingault crater, whose floor is overlapped by the Nectarian ejecta. The main part of ellipse 8 is located on the Imbrian plain formed by the ejecta of Schomberger crater, which is a potential source of material located under the SPA cover. Ellipses 9 and 10 are almost entirely overlaid by the Imbrian ejecta from Moretus crater. The crater is a potential source of the ancient pre-Nectarian material located under the SPA ejecta. In ellipse 9, of interest is the various morphology of the surface, including the topography classes $\mathrm{p}, \mathrm{pc}, \mathrm{rp}, \mathrm{h}, \mathrm{c}$, and $\mathrm{s}$. The photogeological analysis of the images made at this landing site could have been extremely important for interpreting the geological history in the southern polar region. Ellipse 11 was positioned in pre-Nectarian Boguslawsky crater C. Like ellipse B2, ellipse B1 is found in one crater, a few tens of kilometers from each other; however, B1 exhibits the more variegated morphological structure of the terrain that was partly overlaid by the ejecta from the Imbrian crater.

\section{CONCLUSIONS}

The alternate sites and a few parameters of the primary landing sites of Luna-Glob spacecraft were analyzed (Luna-25). The engineering-technical requirements for conditions of soft landing and long-term operation at the lunar pole, as well as the scientific component of the mission were considered.

For safe lunar landing at the landing site, it is required to estimate the topography of the flight path to the ellipse, to calculate the inclinations on the surface and the probability of encountering rocks at a landing site. The ultimate potential hazard of the topography in the descent path of the spacecraft should be evaluated during the final calculation of the orbit; therefore, we should keep in mind that ellipses 2, $3,9,10, \mathrm{~B} 1$, and $\mathrm{B} 2$ are located on the crater floor. To avoid a roll-over of the spacecraft, the inclination on the surface should not exceed $10^{\circ}$ at the base of $\sim 3 \mathrm{~m}$. The ellipses with the plain topography include primary 1, 4, 6 and secondary 2, 3, 5 landing ellipses. The measurements of the surface inclinations of alternate ellipses were performed at the base of $60 \mathrm{~m} / \mathrm{px}$. In the near future, it will be necessary to estimate the distributions of inclinations in the ellipses at the base of the footpads of the lander module $(3.5 \mathrm{~m})$. Table 1 shows that the distributions of the inclinations at the base of 60 and $3.5 \mathrm{~m}$ do not correlate with each other, and the estimation of the distribution of the inclinations at the base of $3.5 \mathrm{~m}$ may lead to a change in the priority degree of the ellipses considered. The latter are characterized by a small content of rocks. There is a slight increase in rock content in a few relatively fresh craters and ejecta from them in ellipses 2, 3, and B2; however, the area of these craters from the entire ellipse is minor and may be disregarded.

The highest average concentration of WEH is typical of ellipses 7 and 10 with the values $0.19 \pm 0.02(1 \sigma)$ and $0.14 \pm 0.01(1 \sigma)$ wt $\%$, respectively. Based on the integrated geological and geomorphological analysis with respect to the engineering-technical requirements and scientific significance, we identified the high-priority landing ellipses $(1,3,4,6$, and 8). Ellipses 5, 7, 9, 10, 11, as well as B1 and B2 are least suitable for landing.

\section{OPEN ACCESS}

This article is licensed under a Creative Commons Attribution 4.0 International License, which permits use, sharing, adaptation, distribution and reproduction in any medium or format, as long as you give appropriate credit to the original author(s) and the source, provide a link to the Creative Commons license, and indicate if changes were made. The images or other third party material in this article are included in the article's Creative Commons license, unless indicated otherwise in a credit line to the material. If material is not included in the article's Creative Commons license and your intended use is not permitted by statutory regulation or exceeds the permitted use, you will need to obtain permission directly from the copyright holder. To view a copy of this license, visit http://creativecommons.org/licenses/by/4.0/.

\section{REFERENCES}

Abdrakhimov, A.M., Basilevsky, A.T., Ivanov, M.A., Kokhanov, A.A., Karachevtseva, I.P., and Head, J.W., Occurrence probability of slopes on the lunar surface: Estimate by the shaded area percentage in the LROC NAC images, Sol. Syst. Res., 2015, vol. 49, no. 5, pp. $285-294$.

https://doi.org/10.7868/S0320930X15050011

Bandfield, J.L., Ghent, R.R., Vasavada, A.R., Paige, D.A., Lawrence, S.J., and Robinson, M.S., Lunar surface rock abundance and regolith fines temperatures derived from LRO Diviner Radiometer data, J. Geophys. Res.: Planets, 2011, vol. 116, pp. 1-18.

https://doi.org/10.1029/2011JE003866

Demidov, N.E. and Basilevsky, A.T., Height-to-diameter ratios of moon rocks from analysis of Lunokhod-1 and -2 and Apollo 11-17 panoramas and LROC NAC images, Sol. Syst. Res., 2014, vol. 48, no. 5, pp. 324-329.

https://doi.org/10.1134/S0038094614050013 
Djachkova, M.V., Litvak, M.L., Mitrofanov, I.G., and Sanin, A.B., Selection of Luna-25 landing sites in the south polar region of the Moon, Sol. Syst. Res., 2017, vol. 51, no. 3 , pp. $185-195$. https://doi.org/10.1134/S0038094617030029

Feldman, W.C., Maurice, S., Lawrence, D.J., Little, R.C., Lawson, S.L., Gasnault, O., Wiens, R.C., Barraclough, B.L., Elphic, R.C., Prettyman, T.H., Steinberg, J.T., and Binder, A.B., Evidence for water ice near the Lunar poles, J. Geophys. Res.: Planets, 2001, vol. 106, pp. 23231-23251. https://doi.org/10.1029/2000JE001444

Housen, K.R., Schmidt, R.M., and Holsapple, K.A., Crater ejecta scaling laws: Fundamental forms based on dimensional analysis, J. Geophys. Res.: Solid Earth, 1983, vol. 88 , pp. $2485-2499$. https://doi.org/10.1029/JB088iB03p02485

Ivanov, M.A., Abdrakhimov, A.M., Basilevsky, A.T., Demidov, N.E., Djachkova, M.V., Guseva, E.N., Head, J.W., Hiesinger, H., Kohanov, A.A., Krasilnikov, S.S., and Mitrofanov, I.G., Geological characterization of the three high-priority landing sites for the Luna-Glob mission, Planet. Space Sci., 2018, vol. 162, pp. 190-206.

Ivanov, M.A., Basilevsky, A.T., Bricheva, S.S., Guseva, E.N., Demidov, N.E., Zakharova, M., and Krasil'nikov, S.S., Fundamental problems of lunar research, technical solutions, and priority lunar regions for research, Sol. Syst. Res., 2017, vol. 51, no. 6, pp. 441-456. https://doi.org/10.1134/S0038094617060041

Ivanov, M.A., Hiesinger, H., Abdrakhimov, A.M., Basilevsky, A.T., Head, J.W., Pasckert, J.H., Bauch, K., van der Bogert, C.H., Gläser, P., and Kohanov, A., Landing site selection for Luna-Glob mission in crater Boguslawsky, Planet. Space Sci., 2015, vol. 117, pp. 45-63. https://doi.org/10.1016/j.pss.2015.05.007

Krasilnikov, S.S., Basilevsky, A.T., Ivanov, M.A., Abdrakhimov, A.M., and Kokhanov, A.A., Steepness of slopes at the Luna-Glob landing sites: Estimating by the shaded area percentage in the LROC NAC images, Sol. Syst. Res., 2018, vol. 52, no. 2, pp. 87-97. https://doi.org/10.1134/S0038094618010045

Li, S., Lucey, P.G., Milliken, R.E., Hayne, P.O., Fisher, E., Williams, J.-P., Hurley, D.M., and Elphic, R.C., Direct evidence of surface exposed water ice in the lunar polar regions, Proc. Natl. Acad. Sci. U.S.A., 2018, vol. 115 , pp. $8907-8912$.

https://doi.org/10.1073/pnas.1802345115
Melosh, H.J., Impact Cratering: A Geologic Process, New York: Oxford Univ. Press, 1989.

Mitrofanov, I.G., Sanin, A.B., Boynton, W.V., Chin, G., Garvin, J.B., Golovin, D., Evans, L.G., Harshman, K., Kozyrev, A.S., Litvak, M.L., Malakhov, A., Mazarico, E., McClanahan, T., Milikh, G., Mokrousov, M., et al., Hydrogen mapping of the lunar south pole using the LRO neutron detector experiment LEND, Science, 2010, vol. 330, no. 6003, pp. 483-486.

https://doi.org/10.1126/science.1185696

Paige, D.A., Foote, M.C., Greenhagen, B.T., Schofield, J.T., Calcutt, S., Vasavada, A.R., Preston, D.J., Taylor, F.W., Allen, C.C., Snook, K.J., Jakosky, B.M., Murray, B.C., Soderblom, L.A., Jau, B., Loring, S., et al., The lunar reconnaissance orbiter diviner lunar radiometer experiment, Space Sci. Rev., 2010, vol. 150, pp. 125-160. https://doi.org/10.1007/s11214-009-9529-2

Robinson, M.S., Brylow, S.M., Tschimmel, M., Humm, D., Lawrence, S.J., Thomas, P.C., Denevi, B.W., BowmanCisneros, E., Zerr, J., Ravine, M.A., Caplinger, M.A., Ghaemi, F.T., Schaffner, J.A., Malin, M.C., Mahanti, P., et al., Lunar reconnaissance orbiter camera (LROC) instrument overview, Space Sci. Rev., 2010, vol. 150, nos. 1-4, pp. $81-124$.

Sanin, A.B., Mitrofanov, I.G., Litvak, M.L., Bakhtin, B.N., Bodnarik, J.G., Boynton, W.V., Chin, G., Evans, L.G., Harshman, K., Fedosov, F., Golovin, D.V., Kozyrev, A.S., Livengood, T.A., Malakhov, A.V., McClanahan, T.P., et al., Hydrogen distribution in the lunar polar regions, Icarus, 2017, vol. 283, pp. 20-30. https://doi.org/10.1016/j.icarus.2016.06.002

Sharpton, V.L., Outcrops on lunar crater rims: Implications for rim construction mechanisms, ejecta volumes and excavation depths, J. Geophys. Res.: Planets, 2014, vol. 119 , pp. $154-168$. https://doi.org/10.1002/2013JE004523

Smith, D.E., Zuber, M.T., Jackson, G.B., Cavanaugh, J.F., Neumann, G.A., Riris, H., Sun, X., Zellar, R.S., Coltharp, C., Connelly, J., Katzigor, R.B., Kleyner, P., Liiva, P., Matuszeski, A., Mazarico, E.M., et al., The lunar orbiter laser altimeter investigation on the lunar reconnaissance orbiter mission, Space Sci. Rev., 2010, vol. 150 , pp. $209-241$.

https://doi.org/10.1007/s11214-009-9512-y

Wilhelms, D.E. and McCauley, J.F., Geologic map of the near side of the Moon, in US Geological Survey Map I-703, 1971.

Translated by L. Mukhortova 